\title{
The vascular endothelium: the cornerstone of organ dysfunction in severe SARS-CoV-2 infection
}

\author{
Stéphanie Pons ${ }^{1,2}$, Sofiane Fodil ${ }^{3}$, Elie Azoulay ${ }^{3}$ and Lara Zafrani ${ }^{1,3^{*}}$
}

\begin{abstract}
In severe SARS-CoV-2 infections, emerging data including recent histopathological studies have emphasized the crucial role of endothelial cells (ECs) in vascular dysfunction, immunothrombosis, and inflammation.

Histopathological studies have evidenced direct viral infection of ECs, endotheliitis with diffuse endothelial inflammation, and micro- and macrovascular thrombosis both in the venous and arterial circulations. Venous thrombotic events, particularly pulmonary embolism, with elevated D-dimer and coagulation activation are highly prevalent in COVID-19 patients. The pro-inflammatory cytokine storm, with elevated levels of interleukin-6 (IL-6), IL-2 receptor, and tumor necrosis factor-a, could also participate in endothelial dysfunction and leukocyte recruitment in the microvasculature. COVID-19-induced endotheliitis may explain the systemic impaired microcirculatory function in different organs in COVID-19 patients. Ongoing trials directly and indirectly target COVID-19-related endothelial dysfunctions: i.e., a virus-cell entry using recombinant angiotensin-converting enzyme 2 (ACE2) and transmembrane protease serine 2 (TMPRSS-2) blockade, coagulation activation, and immunomodulatory therapies, such as anti-IL-6 strategies. Studies focusing on endothelial dysfunction in COVID-19 patients are warranted as to decipher their precise role in severe SARS-CoV-2 infection and organ dysfunction and to identify targets for further interventions.
\end{abstract}

Keywords: SARS-CoV-2, COVID-19, Endothelial cells, Endothelial dysfunction, Cytokines, Thrombosis

\section{Background}

Since December 2019, a novel betacoronavirus named SARS-CoV-2 (severe acute respiratory syndrome coronavirus-2) has caused a global outbreak of respiratory illness described as COVID-19. SARS-CoV 2 infection induces a viral pneumonia that leads to acute respiratory failure in up to $20 \%$ of symptomatic patients $[1,2]$. At early stages of the pandemic, little attention has been paid to endothelial dysfunction in severe SARS-CoV-2 infection. Yet, endothelial cells

\footnotetext{
* Correspondence: lara.zafrani@aphp.fr

'INSERM U976, Human Immunology, Pathophysiology and Immunotherapy,

Saint-Louis Teaching Hospital, Paris University, Paris, France

${ }^{3}$ Department of Medical Intensive Care Unit, Saint-Louis Teaching Hospital,

Assistance Publique des Hôpitaux de Paris, 1, Avenue Claude Vellefaux, 75010 Paris, France

Full list of author information is available at the end of the article
}

(ECs) have a crucial role in several physiologic processes. They control blood rheology, vasomotor tone regulation, osmotic balance, and vascular barrier function $[3,4]$. The endothelium has also a key role in setting up the innate immune response in a wide array of critical care conditions, such as sepsis, but it exhibits intrinsic properties involved in the activation of adaptive immunity [5-7]. ECs represent an important target for infection of most human viruses, enhancing immune response, inducing increased tissue permeability, inflammation, and contributing to the severity of the viral disease [8]. Indeed, ECs in humans basally express both class I and class II MHC molecules [9]. Thus, they are able to process antigens (Ag) and act as antigenpresenting cells. ECs cannot activate naïve lymphocytes but can mediate Ag-specific stimulation of Ag effector or

(c) The Author(s). 2020 Open Access This article is licensed under a Creative Commons Attribution 4.0 International License, which permits use, sharing, adaptation, distribution and reproduction in any medium or format, as long as you give appropriate credit to the original author(s) and the source, provide a link to the Creative Commons licence, and indicate if changes were made. The images or other third party material in this article are included in the article's Creative Commons licence, unless indicated otherwise in a credit line to the material. If material is not included in the article's Creative Commons licence and your intended use is not permitted by statutory regulation or exceeds the permitted use, you will need to obtain permission directly from the copyright holder. To view a copy of this licence, visit http://creativecommons.org/licenses/by/4.0/ The Creative Commons Public Domain Dedication waiver (http://creativecommons.org/publicdomain/zero/1.0/) applies to the data made available in this article, unless otherwise stated in a credit line to the data. 
memory CD4 and CD8 lymphocytes [10-12]. Moreover, endothelial dysfunction is known to be highly involved in organ dysfunction during viral infections, as it induces a pro-coagulant state, microvascular leak, and organ ischemia [13]. In SARS-CoV-2 infections, emerging data including recent histopathological studies have highlighted the crucial role of ECs in vascular dysfunction, inflammation, and (immuno) thrombosis $[14,15]$.

\section{Histological evidence of endothelial dysfunction during SARS-CoV-2 infection}

In vitro, SARS-CoV-2 is able to directly infect engineered human blood vessel organoids [16]. In three patients infected with SARS-CoV-2, Varga et al. described endothelial cell involvement in different organs, including the kidney, lung, heart, and liver. They found evidence of viral inclusion structures in ECs, as well as endothelial inflammation with the recruitment of neutrophils and mononuclear cells. Indeed, by electron microscopy, they identified viral inclusion in endothelial cells from a transplanted kidney. In another critically ill patient with multi-organ failure, post-mortem histology revealed lymphocytic endotheliitis in the same organs. In another COVID-19 patient with mesenteric ischemia, histology of the small intestine resection disclosed prominent endotheliitis of the submucosal vessels with evidence of direct viral infection of the ECs and diffuse endothelial inflammation with mononuclear cell infiltrate. Authors suggest that COVID-19-induced endotheliitis may explain the systemic impaired microcirculatory function in different organs in COVID-19 patients [14]. Severe COVID-19 is associated with cytokine secretion and immune cell recruitment that undoubtedly result in EC activation

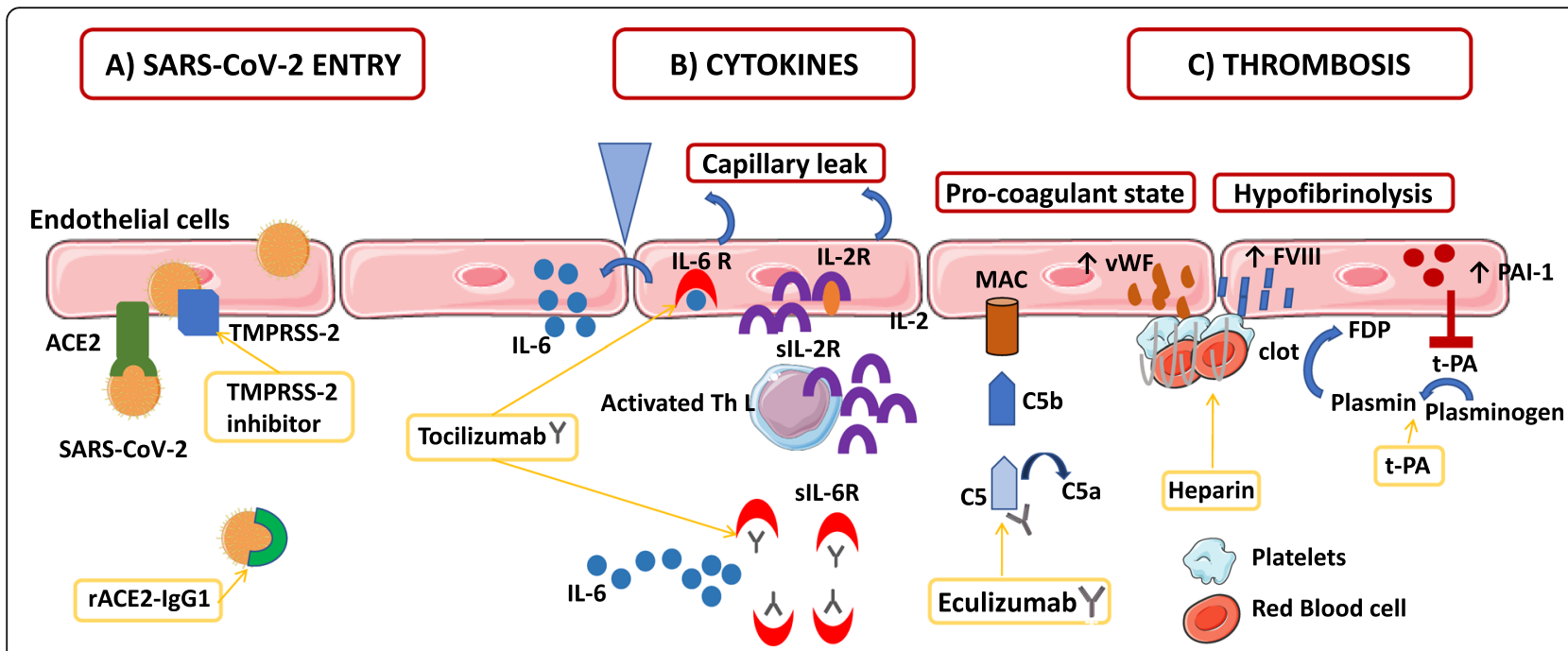

Fig. 1 The role of endothelial cells in SARS-CoV-2 infection and treatment. a Severe acute respiratory syndrome coronavirus 2 (SARS-CoV-2) binds with Angiotensin- converting enzyme 2 (ACE2) on the cell membrane of the host cells. Cell invasion also depends on the presence of the protease Transmembrane protease serine 2 (TMPRSS-2) that is able to cleave the viral spike. The recombinant protein of human ACE2 fused with the FC region of the human immunoglobulin IgG1 (rACE2-IgG1) binds with high affinity to the receptor-binding domain of SARS-CoV-2. Moreover, a protease TMPRSS2 inhibitor is efficient to block SARS-CoV-2 entry into the endothelial cells (ECS). $\mathbf{b}$ In patients diagnosed with severe COVID-19, increased levels of pro-inflammatory cytokines, in particular, the soluble interleukin 2-receptor (IL-2R) and interleukin-6 (IL-6) have been observed. ECs express both IL-6 receptor (IL-6R) and IL-2R on their surface. Soluble IL-2R (sIL-2R) is mostly secreted by activated T helper lymphocytes, but might be also secreted by ECs. Binding of IL-6 and IL-2 on their receptors induces a capillary leak. Moreover, IL- 6 signaling induces the secretion by ECs of more IL-6 and other cytokines. Tocilizumab, a humanized anti-IL-6 receptor (IL-6R) antibody that inhibits signal transduction by binding sIL-6R and membrane-bound IL-6R, has emerged as a potential immunomodulatory treatment in COVID-19 patients. C During SARS-CoV-2 infection, endothelial dysfunction and microthrombi formation may be secondary to complement activation and membrane attack complexes deposits on ECs. Eculizumab, a human monoclonal antibody designed to bind to the complement protein C5 with high affinity prevents the generation of the terminal membrane attack complex. EC activation also induces a pro-coagulant state by increasing their production of von Willebrand factor (VWF) and factor VIII (FVIII), which participate in clot formation. Heparin from prophylactic to therapeutic doses has been used in COVID-19 patients to inhibit clot formation. Moreover, during SARS-CoV-2 infection, ECs increase their production of plasminogen activator inhibitor 1 (PAl-1), which inhibits the conversion of plasminogen to plasmin and the degradation of clots inducing a hypofibrinolytic state. Tissue plasminogen activator (t-PA) has been tested in COVID-19 patients for its fibrinolytic effect. ACE2: angiotensinconverting enzyme 2; C5: complement C5; FVIII: factor VIII; FDP: fibrin degradation product; IL-2: interleukin-2; IL-6: interleukin-6; IL-2R: interleukin-2 receptor; IL-6-R: interleukin-6 receptor; MAC: membrane attack complex; PAI 1: plasminogen activator inhibitor 1; rACE2-lgG1: recombinant angiotensin-converting enzyme 2 immunoglobulin G1; SARS-Cov-2: severe acute respiratory syndrome coronavirus 2; slL-2R: soluble interleukin 2 receptor, sIL-6R: soluble interleukin 6 receptor; Th L: T helper lymphocyte; TMPRSS-2: transmembrane protease serine 2 t-PA: tissue plasminogen activator; vWF: von Willebrand factor 
[17]. Given the fundamental role of ECs in maintaining homeostasis, vascular permeability, and blood rheology, EC dysfunction may actively participate in thrombo-inflammatory processes that ultimately result in COVID-19 vasculopathy, ventilation-perfusion mismatch, and a clinical phenotype of refractory ARDS [18].

In a post-mortem histopathological analysis of 26 patients who died because of SARS-CoV-2 infection, $\mathrm{Su}$ et al. found evidence of coronavirus particles in the tubular epithelium and podocytes but not in renal ECs. However, they found endothelial cell swelling with foamy degeneration in five patients. Among them, three patients had a few areas of segmental fibrin thrombus in glomerular capillary loops associated with a severe endothelial injury. Whether these findings are indicative of specific endothelial injury due to SARS-CoV-2 invasion or should they reflect the severity of underlying conditions such as hypertension or diabetes that are present in more than half of severe COVID-19 patients is unclear [19]. In postmortem lung biopsies performed in 6 patients who died from SARS-CoV-2 infection, Copin et al. showed that vascular injury was also a prominent feature, demonstrated by endothelial injury with cytoplasmic vacuolization and cell detachment in small to medium-sized pulmonary arteries [20].

\section{Entry of SARS-CoV-2 into endothelial cells}

Angiotensin-converting enzyme 2 (ACE2) is a homolog of ACE that converts angiotensin II to angiotensin 1-7, which alleviates renin-angiotensin system-related vasoconstriction. SARS-CoV-2 binds with ACE2 on the cell membrane of the host cells. ACE2 has been found in arterial and venous endothelial cells in various human tissues, including the oral and nasal mucosa, lung, small intestine, colon, skin, lymph nodes, thymus, bone marrow, spleen, kidney, and brain [21]. ACE2 presence on the endothelia of various organs does not necessarily imply that SARS-CoV-2 invades all organs. Indeed, evidence of virus invasion has not been found in all human tissues even though ACE2 receptors are ubiquitous. Cell entry of coronavirus, which mainly occurs through endocytosis, depends also on the binding of the viral spike (S) proteins to cellular receptors and on $S$ protein priming by host cell proteases [22]. Therefore, cell invasion depends on both ACE2 expression and the availability of the protease transmembrane protease serine 2 (TMPRSS-2), or other proteases, to cleave the viral spike [23]. TMPRSS-2 has been also previously shown to be expressed in human endothelial cells, but its expression may vary among microvascular and macrovascular beds and across organs [24].

\section{Cytokines and endothelial activation during SARS-CoV-2 infection}

ECs display important immunologic functions. They participate in the regulation of local and systemic inflammatory and immune reactions $[17,25]$. Thus, ECs can interact with complement, chemokines, or humoral components and generate or respond to cytokines [3]. Cytokines and chemokines have long been thought to play an important role in immunity and immunopathology during virus infections, such as influenza or coronavirus infections [26, 27].

Cytokine release syndrome (CRS) is a systemic inflammatory response, which can be caused by an infection, some drugs, or cancers and is characterized by a major increase in the level of a large number of proinflammatory cytokines. CRS was found to be the major cause of morbidity in patients infected with SARS and Middle East respiratory syndrome coronavirus (MERS$\mathrm{CoV}$ ) [27]. In patients diagnosed with severe COVID-19, increased levels of pro-inflammatory cytokines, in particular the soluble interleukin 2 receptor (IL-2R), interleukin-6 (IL-6), and tumor necrosis factor- $\alpha$ (TNF$\alpha)$, have been observed [28]. However, as noticed by Leisman et al. [29], in COVID-19 patients, plasmatic concentrations of cytokines, especially IL-6, are much lower than in typical hyper-inflammatory ARDS or in CRS and should be distinguished from them [30, 31].

IL-6 is a major highly inducible pro-inflammatory cytokine secreted by several different cell types including monocytes, lymphocytes, fibroblasts, and ECs [32, 33]. The main activators of IL- 6 expression are interleukin$1 \beta$ (IL-1 $\beta$ ) and TNF- $\alpha$, viral infection, and angiotensin II [34-36]. IL-6 plays a major role in EC activation during the early phase of inflammation. Thus, IL- 6 induces an increased vascular permeability, the secretion of proinflammatory cytokine/chemokines by ECs (IL-6, IL-8, and monocyte chemoattractant protein-1 (MCP-1)), and the activation of C5a complement [37, 38]. In COVID19 patients, levels of IL- 6 seem directly correlated with the severity of the disease $[28,39,40]$. These findings were confirmed in a recent meta-analysis of observational Chinese studies [28, 41-46]. Moreover, levels of IL-6 were significantly associated with mortality. In this study, the authors suggest that IL- 6 dosage should be performed to all patients diagnosed with COVID-19 and that the existing scoring system should be customized using IL-6 concentrations [41].

Another important cytokine with increased serum levels observed in COVID-19 is the soluble IL-2R [28, 47]. As for IL-6, levels of soluble IL-2R seem to be correlated with the severity of the disease [47, 48]. Interleukin-2 is mostly secreted by activated T-helper lymphocytes and exerts both stimulatory and regulatory immune functions [49-51]. IL-2 mediates its activity by 
binding to IL-2R. A lot of different immune cells are expressing the IL-2R at their surface: activated T lymphocytes, regulatory $\mathrm{T}$ cells, activated $\mathrm{B}$ cells, monocytes, and natural killer cells $[52,53]$. The soluble form of the IL-2R seems to be produced by proteolytic cleavage of IL-2R $\alpha$, and the release of soluble IL-2R into the circulation is proportional to its membrane expression [54, 55]. Serum levels of soluble IL-2R reflect the immune cell activation in various inflammatory or malignant diseases $[56,57]$. It has been also demonstrated that endothelial pulmonary cells express IL-2R on their surface and that IL-2 could bind to endothelial cells and induce a pulmonary-edema in response to this binding [58]. Thus, IL-2R increased serum levels could be induced by the endothelial cells IL-2R expression and IL-2 response might be implicated in the pathophysiology of COVID19 by a direct action on the endothelium.

Finally, pro-inflammatory cytokines, in particular, IL$1 \beta$, IL-6, and TNF $\alpha$, which are elevated in patients with COVID-19 induce the loss of the normal antithrombotic and anti-inflammatory functions of endothelial cells, leading to coagulation dysregulation, complement and platelet activation, and leukocyte recruitment in the microvasculature [17].

\section{Thrombotic events in COVID-19 are associated with endothelial cell dysfunction}

A remarkable characteristic of patients suffering from severe COVID-19 is the high prevalence of acute thrombotic events. Indeed, several authors have reported acute thrombosis, mainly venous thrombosis and pulmonary embolism in COVID-19 patients. In a cohort of 150 critically ill patients, Helms et al. reported a prevalence of $16.7 \%$ of pulmonary embolism and only $2 \%$ of deep vein thrombosis [15]. Lodigiani et al. reported that the majority of thrombotic complications were venous and primarily represented by isolated pulmonary embolism [59]. Last, Klok et al. reported a $31 \%$ prevalence of thrombotic events in a cohort of 184 critically ill patients [60].

Patients without macrovascular thrombosis, venous or arterial, present with widespread microvascular thrombosis. Histological data have highlighted the role of capillary thrombosis in the pathogenesis of organ dysfunction during SARS-CoV-2 infection. Segmental fibrin thrombi have been found in glomerular capillary loops [19], small fibrinous thrombi in small pulmonary arterioles in areas of both damaged and more preserved lung parenchyma [61], small fibrinous thrombi in the superficial dermal vessels [61], thrombosis of intra-septal microvessels [2], small-sized arterioles with complete luminal thrombosis and occlusive thrombosis of intraseptal capillaries, and medium-sized arteries with complete luminal thrombosis [2].
This high prevalence of pulmonary embolism without deep vein thrombosis, widespread microthrombosis, and fibrin diffuse deposits [62] could be in favor of a dysregulation of coagulation homeostasis initially in the lung that can spread across the body [2]. However, in a recent cohort of 12 consecutive COVID-19-positive deaths, an autopsy revealed deep venous thrombosis in seven of 12 patients (58\%) and pulmonary embolism was the direct cause of death in four patients. Moreover, in six of the nine men included in the study, fresh thrombosis was also present in the prostatic venous plexus [63].

Several studies reported coagulation activation, especially in critically ill patients with SARS-CoV-2 infection. Tang et al. reported that among 183 patients, the nonsurvivors had significantly higher D-dimer and fibrin degradation product (FDP) levels, longer prothrombin time, and activated partial thromboplastin time compared to survivors [64]. Helms et al. found that most patients (>95\%) had elevated D-dimer and fibrinogen levels, but none of them had a positive International Society on Thrombosis and Haemostasis (ISTH) disseminated intravascular coagulation (DIC) score. Moreover, the sepsis-induced coagulopathy score, which detects patients at risk of developing DIC, was positive in only $14.7 \%$ of patients. Interestingly, the von Willebrand factor (vWF) activity and vWF antigen (vWF Ag) were considerably increased, as well as factor VIII, indicating inflammation-mediated endothelial activated procoagulant state [15]. The main fibrinolytic inhibitor described in the pathogenesis of ARDS is plasminogen activator inhibitor 1 (PAI-1), which is known to be elevated in severe acute respiratory syndrome coronavirus (SARS$\mathrm{CoV}$ ) indicating a hypofibrinolytic state associated with the pro-coagulant state [65]. Moreover, direct viral invasion of ECs or indirect activation mediated by complement [66] could be responsible for EC dysfunction and exocytosis of unusually large vWF multimers, as well as platelet activation, leading to microthrombogenesis [67]. Magro et al. described that complement deposition in the lungs of five COVID-19 patients was associated with microvascular injury and thrombosis [68]. The association of the clinical phenotype of COVID-19 respiratory failure, the dysregulated coagulation system with a hypercoagulable state, and elevated endothelial surrogate markers suggests a crucial role played by endothelial damage and inflammation during severe SARS-CoV-2 infection [67].

\section{The endothelium as a therapeutic target in severe COVID-19 patients}

To date, COVID-19 patients' management is only limited to symptomatic or palliative treatments. Ongoing trials directly and indirectly target COVID-19-related endothelial dysfunctions: i.e., a virus-cell entry using 
recombinant ACE2 and TMPRSS-2 blockade, immunomodulatory therapies such as anti-IL-6 strategies, complement blockade, and coagulation activation (Fig. 1).

\section{SARS-CoV-2 entry in endothelial cells}

The SARS-CoV-2 virus uses ACE2 and TMPRSS2 to infect cells. Thus, the TMPRSS2 blockade has been proposed as a potential treatment. A protease TMPRSS2 inhibitor, already approved for clinical use, has been tested in vitro and is efficient to block SARS-CoV-2 entry into the cells [23]. Recombinant ACE2 (rACE2) is also a molecule of interest in the treatment of COVID-19. Indeed, rACE2 was shown to have therapeutic potential for the SARS-CoV [69]. However, rACE2 exhibits a fast clearance rate, with a half-life of only hours reported by pharmacokinetic studies. Thus, Lei et al. tested the recombinant protein of the extracellular domain of human ACE2 fused with the Fc region of the human immunoglobulin IgG1. This protein has better pharmacological properties and binds with high affinity to the receptor-binding domain of SARS-CoV and SARS$\mathrm{CoV}-2$. This recent study supports further investigation of ACE2-Ig for diagnosis, prophylaxis, and treatment of SARS-CoV-2 [70]. Some authors have also suggested that renin-angiotensin aldosterone system inhibitors could be a potential treatment of COVID-19, because of the RAAS activation and the key interaction between SARS-CoV-2 and ACE2 (Clinical Trial NCT04311177). However, the balance between circulating ACE2 and membrane-bound ACE2 receptor may be crucial to prevent SARS-CoV-2 entry into target cells which depends on membrane-bound ACE2 receptors [71].

\section{Immunomodulatory treatments}

Corticosteroids are stress-hormones with strong antiinflammatory activities. They influence the function of various subtypes of immune cells including $\mathrm{T}$ cells, dendritic cells, macrophages, and $B$ cells and endothelial cells [72, 73]. Based on previous studies on the use of corticosteroids in SARS, H1N1, and other viral pneumonia, the routine use of glucocorticoids in COVID-19 is not supported by the World Health Organization [74, 75]. Surviving sepsis guidelines recommend to use corticosteroids only for patients in whom adequate fluids, and vasopressor therapy do not restore hemodynamic stability [76]. A recent observational Chinese study of 31 severe COVID-19 patients including 11 treated by corticosteroids found no association between therapy and outcomes in patients without ARDS [77]. However, in a cohort observational study including 201 patients in China, treatment with methylprednisone was beneficial to patients with ARDS [78]. Prospective-controlled randomized studies are ongoing to better determine the place of glucocorticoids in the management of COVID-19 patients (Clinical Trials NCT04344288,
NCT04381936, NCT04344730, NCT04348305, and NCT04343729).

Tocilizumab, a humanized anti-IL-6 receptor (IL-6R) antibody that inhibits signal transduction by binding soluble IL-6R and membrane-bound IL-6R, has emerged as a potential immunomodulatory treatment in COVID-19 patients [79]. Two prospective studies without a control arm included respectively 20 and 63 patients with severe or critical COVID-19. Both studies found clinical and biological improvements in patients treated with tocilizumab without obvious adverse reactions $[80,81]$. The results from a multicenter randomized clinical trial designed to determine the efficacy and tolerance of tocilizumab in patients with moderate, severe pneumonia, or critical pneumonia associated with COVID-19 is should be disclosed in a close future (Clinical Trial NCT04331808).

\section{Endothelial dysfunction and pro-thrombotic state}

As reviewed in paragraph 3, COVID-19 is frequently associated with thrombotic complications, both in the venous and arterial circulations. Endothelial dysfunction induced by SARS-CoV-2 infection results in a prothrombotic state leading to occlusion and microthrombi formation in COVID-19 patients, encouraging the use of prophylactic or even therapeutic anti-coagulation therapies. First, all hospitalized COVID-19 patients should have coagulation tests performed on admission, as it can provide useful prognosis information and help guide the anticoagulant therapy [64, 82, 83]. Tang et al. demonstrated that the use of prophylactic anticoagulant therapy was associated with a decreased mortality in COVID-19 patients [84]. In various national or international guidelines, it has been admitted that all confirmed or suspected COVID-19 patients admitted to the hospital should be treated with venous thrombosis event prophylaxis, in the absence of contra-indication [83, 85]. The dose of anticoagulation for prophylaxis has also been increased by many teams to "intermediate intensity" doses such as $0.5 \mathrm{mg} / \mathrm{kg}$ twice a day of enoxaparin, using a risk-adapted strategy based on levels of D-dimer, fibrinogen, ICU location, obesity, or other factors associated with increased risk [85, 86]. The concept of using full-dose anticoagulation in COVID-19 patients for preventing microvascular thrombosis during severe infection has been also considered [85]. To date, data are scarce to support either one or the other strategy. Moreover, heparin exhibits non-anticoagulant effects as abilities to bind to inflammatory cytokines, to inhibit neutrophil chemotaxis and leukocyte migration through the endothelium, to neutralize the positively charged peptide complement factor $\mathrm{C} 5 \mathrm{a}$, and to sequester acute phase proteins $[87,88]$. Thus, heparin anti-inflammatory functions may also be relevant in COVID-19 patients. Furthermore, Wang et al. have also reported the use of 
fibrinolytic agent, tissue plasminogen activator, in 3 critically ill patients, with a transient improvement of their respiratory status [89]. Eculizumab is a human monoclonal antibody designed to bind to the complement protein C5 with high affinity prevents the generation of the terminal complement complex C5b-9, which is involved in cell lysis [90]. Complement inhibition has been shown to be an effective therapeutic target in hematological and neuroinflammatory diseases $[91,92]$. An Italian preliminary report of four severe COVID-19 patients treated by eculizumab recovered after treatment [93]. Currently, two French studies are testing eculizumab in SARS-CoV-2 infection, hypothesizing that complement activation may be a key player in COVID-19 infectionrelated EC dysfunction and multi-organ failure (Clinical Trials NCT04346797 and NCT04355494).

\section{Conclusion}

Emerging data suggest a crucial role of endothelial dysfunction during SARS-CoV-2 infection, as a direct target of the virus and inflammatory cytokines as well as the main actor in orchestrating a pro-inflammatory and procoagulant state in COVID-19 patients. Promising therapies that impact endothelial dysfunction are currently under evaluation.

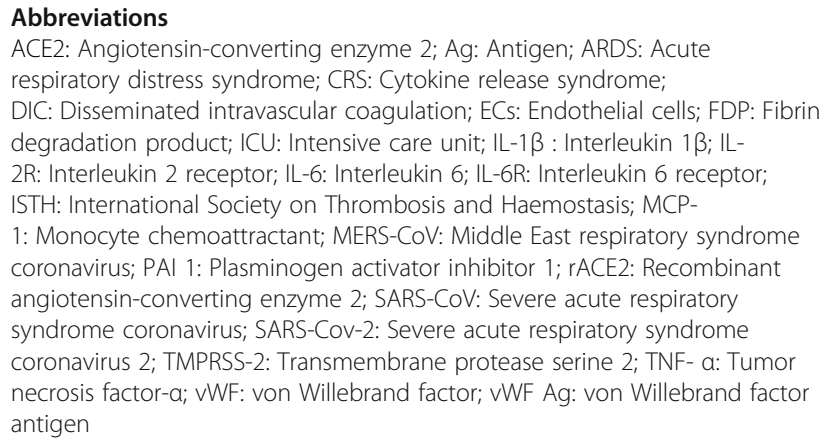

\section{Acknowledgements}

Not applicable

\section{Authors' contributions}

$\mathrm{SP}, \mathrm{SF}, \mathrm{EA}$, and LZ equally participated in the writing of the manuscript. The authors read and approved the final manuscript.

\section{Funding}

No funding

\section{Availability of data and materials \\ Not applicable}

\section{Ethics approval and consent to participate}

Not applicable

\section{Consent for publication}

Not applicable

\section{Competing interests}

$\mathrm{SP}$ received a research grant from the French Intensive Care Society, one from the European Society of Intensive Care Medicine, and one from the
Zoll foundation. EA has received fees for lectures from MSD, Pfizer, and Alexion. His institution and research group have received support from Baxter, Jazz Pharma, Fisher\&Payckle, Gilead, Alexion, and Ablynx. LZ received a research grant from Jazz Pharma.

\section{Author details}

'INSERM U976, Human Immunology, Pathophysiology and Immunotherapy, Saint-Louis Teaching Hospital, Paris University, Paris, France. ${ }^{2}$ Anesthesia and Critical Care Department, Avicenne Teaching Hospital, Assistance Publique des Hôpitaux de Paris, Bobigny, France. ${ }^{3}$ Department of Medical Intensive Care Unit, Saint-Louis Teaching Hospital, Assistance Publique des Hôpitaux de Paris, 1, Avenue Claude Vellefaux, 75010 Paris, France.

Received: 22 May 2020 Accepted: 4 June 2020

Published online: 16 June 2020

\section{References}

1. Zhu J, Ji P, Pang J, Zhong Z, Li H, He C, et al. Clinical characteristics of 3,062 COVID-19 patients: a meta-analysis. J Med Virol. 2020 [cited 2020 May 5]; Available from: http://doi.wiley.com/10.1002/jmv.25884.

2. Marini JJ, Gattinoni L. Management of COVID-19 respiratory distress. JAMA. 2020 [cited 2020 May 5]; Available from: https://jamanetwork.com/journals/ jama/fullarticle/2765302.

3. Roumenina LT, Rayes J, Frimat M, Fremeaux-Bacchi V. Endothelial cells: source, barrier, and target of defensive mediators. Immunol Rev. 2016;274: 307-29.

4. Daniel AE, van Buul JD. Endothelial junction regulation: a prerequisite for leukocytes crossing the vessel wall. J Innate Immun. 2013;5:324-35.

5. McKenzie JAG, Ridley AJ. Roles of Rho/ROCK and MLCK in TNF-alphainduced changes in endothelial morphology and permeability. J Cell Physiol. 2007;213:221-8.

6. Ley K, Laudanna C, Cybulsky MI, Nourshargh S. Getting to the site of inflammation: the leukocyte adhesion cascade updated. Nat Rev Immunol. 2007;7:678-89.

7. Taflin C, Favier B, Baudhuin J, Savenay A, Hemon P, Bensussan A, et al. Human endothelial cells generate Th17 and regulatory T cells under inflammatory conditions. Proc Natl Acad Sci U S A. 2011;108:2891-6.

8. Teijaro JR, Walsh KB, Cahalan S, Fremgen DM, Roberts E, Scott F, et al. Endothelial cells are central orchestrators of cytokine amplification during influenza virus infection. Cell. 2011;146:980-91.

9. Pober JS, Merola J, Liu R, Manes TD. Antigen presentation by vascular cells. Front Immunol. 2017;8:1907.

10. Ma W, Pober JS. Human endothelial cells effectively costimulate cytokine production by, but not differentiation of, naive CD4+ T cells. J Immunol Baltim Md 1950. 1998;161:2158-67.

11. Perez VL, Henault L, Lichtman AH. Endothelial antigen presentation: stimulation of previously activated but not naïve TCR-transgenic mouse T cells. Cell Immunol. 1998;189:31-40.

12. Sage PT, Varghese LM, Martinelli R, Sciuto TE, Kamei M, Dvorak AM, et al. Antigen recognition is facilitated by invadosome-like protrusions formed by memory/effector T cells. J Immunol Baltim Md 1950. 2012;188:3686-99.

13. Lin G-L, McGinley JP, Drysdale SB, Pollard AJ. Epidemiology and immune pathogenesis of viral sepsis. Front Immunol. 2018;9:2147.

14. Varga Z, Flammer AJ, Steiger $P$, Haberecker M, Andermatt R, Zinkernagel AS, et al. Endothelial cell infection and endotheliitis in COVID-19. Lancet. 2020; 395:1417-8.

15. CRICS TRIGGERSEP Group (Clinical Research in Intensive Care and Sepsis Trial Group for Global Evaluation and Research in Sepsis), Helms J, Tacquard C, Severac F, Leonard-Lorant I, Ohana M, et al. High risk of thrombosis in patients with severe SARS-CoV-2 infection: a multicenter prospective cohort study. Intensive Care Med. 2020 [cited 2020 May 5]; Available from: http:// link.springer.com/10.1007/s00134-020-06062-X.

16. Monteil V, Kwon H, Prado P, Hagelkrüys A, Wimmer RA, Stahl M, et al. Innhibition of SARS-CoV-2 Infections in Engineered Human Tissues Using Clinical-Grade Soluble Human ACE2. Cell. 2020;181(4):905-913.e7. https://doi. org/10.1016/j.cell.2020.04.004.

17. Pons S, Arnaud M, Loiselle M, Arrii E, Azoulay E, Zafrani L. Immune consequences of endothelial cells' activation and dysfunction during sepsis. Crit Care Clin. 2020;36:401-13.

18. McGonagle D, O'Donnell JS, Sharif K, Emery P, Bridgewood C. Immune mechanisms of pulmonary intravascular coagulopathy in COVID-19 
pneumonia [published online ahead of print, 2020 May 7]. Lancet Rheumatol. 2020. https://doi.org/10.1016/S2665-9913(20)30121-1.

19. Su H, Yang M, Wan C, Yi L-X, Tang F, Zhu H-Y, et al. Renal histopathological analysis of 26 postmortem findings of patients with COVID-19 in China [published online ahead of print, 2020 Apr 9]. Kidney Int. 2020;500852538(20)30369-0. https://doi.org/10.1016/j.kint.2020.04.003.

20. Copin MC, Parmentier E, Duburcq T, Poissy J, Mathieu D; Lille COVID-19 ICU and Anatomopathology Group. Time to consider histologic pattern of lung injury to treat critically ill patients with COVID-19 infection. Intensive Care Med. 2020;1-3. https://doi.org/10.1007/s00134-020-06057-8.

21. Hamming I, Timens W, Bulthuis M, Lely A, Navis G, van Goor H. Tissue distribution of ACE2 protein, the functional receptor for SARS coronavirus. A first step in understanding SARS pathogenesis. J Pathol. 2004;203:631-7.

22. Ou X, Liu Y, Lei X, Li P, Mi D, Ren L, et al. Characterization of spike glycoprotein of SARS-COV-2 on virus entry and its immune cross-reactivity with SARS-CoV. Nat Commun. 2020;11:1620.

23. Hoffmann M, Kleine-Weber H, Schroeder S, Krüger N, Herrler T, Erichsen S, et al. SARS-CoV-2 Cell Entry Depends on ACE2 and TMPRSS2 and Is Blocked by a Clinically Proven Protease Inhibitor. Cell. 2020;181(2):271-280.e8. https://doi.org/10.1016/j.cell.2020.02.052.

24. Aimes RT, Zijlstra A, Hooper JD, Ogbourne SM, Sit M-L, Fuchs S, et al. Endothelial cell serine proteases expressed during vascular morphogenesis and angiogenesis. Thromb Haemost. 2003;89:561-72.

25. Pober JS, Sessa WC. Evolving functions of endothelial cells in inflammation. Nat Rev Immunol. 2007;7:803-15.

26. Betakova T, Kostrabova A, Lachova V, Turianova L. Cytokines induced during influenza virus infection. Curr Pharm Des. 2017 [cited 2020 May 5];23. Available from: http://www.eurekaselect.com/150931/article.

27. Channappanavar R, Perlman S. Pathogenic human coronavirus infections: causes and consequences of cytokine storm and immunopathology. Semin Immunopathol. 2017;39:529-39.

28. Chen G, Wu D, Guo W, Cao Y, Huang D, Wang H, et al. Clinical and immunological features of severe and moderate coronavirus disease 2019. J Clin Invest. 2020;130:2620-9.

29. Leisman DE, Deutschman CS, Legrand M. Facing COVID-19 in the ICU: vascular dysfunction, thrombosis, and dysregulated inflammation. Intensive Care Med. 2020 [cited 2020 May 7]; Available from: http://link.springer. com/10.1007/s00134-020-06059-6.

30. Sinha P, Delucchi KL, McAuley DF, O'Kane CM, Matthay MA, Calfee CS. Development and validation of parsimonious algorithms to classify acute respiratory distress syndrome phenotypes: a secondary analysis of randomised controlled trials. Lancet Respir Med. 2020;8:247-57.

31. Maude SL, Frey N, Shaw PA, Aplenc R, Barrett DM, Bunin NJ, et al. Chimeric antigen receptor $\mathrm{T}$ cells for sustained remissions in leukemia. N Engl J Med. 2014;371:1507-17.

32. Jirik FR, Podor TJ, Hirano T, Kishimoto T, Loskutoff DJ, Carson DA, et al. Bacterial lipopolysaccharide and inflammatory mediators augment IL-6 secretion by human endothelial cells. J Immunol Baltim Md 1950. 1989;142:144-7.

33. Baqui AA, Meiller TF, Chon JJ, Turng BF, Falkler WA. Interleukin-6 production by human monocytes treated with granulocyte-macrophage colonystimulating factor in the presence of lipopolysaccharide of oral microorganisms. Oral Microbiol Immunol. 1998;13:173-80.

34. Akira S, Kishimoto+ T. IL-6 and NF-IL6 in acute-phase response and viral infection. Immunol Rev 1992;127:25-50.

35. Cui R, Tieu B, Recinos A, Tilton RG, Brasier AR. RhoA mediates angiotensin IIinduced phospho-Ser536 nuclear factor $\mathrm{KB} /$ RelA subunit exchange on the interleukin-6 promoter in VSMCs. Circ Res. 2006;99:723-30.

36. Hunter CA, Jones SA. IL-6 as a keystone cytokine in health and disease. Nat Immunol. 2015;16:448-57.

37. Desai TR, Leeper NJ, Hynes KL, Gewertz BL. Interleukin-6 causes endothelia barrier dysfunction via the protein kinase C pathway. J Surg Res. 2002;104: $118-23$.

38. Laudes IJ, Chu JC, Huber-Lang M, Guo R-F, Riedemann NC, Sarma JV, et al. Expression and function of $\mathrm{C} 5$ a receptor in mouse microvascular endothelial cells. J Immunol. 2002;169:5962-70.

39. Chen X, Zhao B, Qu Y, Chen Y, Xiong J, Feng Y, et al. Detectable serum SARS-CoV-2 viral load (RNAaemia) is closely correlated with drastically elevated interleukin 6 (IL-6) level in critically ill COVID-19 patients. Clin Infect Dis. 2020; ciaa449.

40. Ruan Q, Yang K, Wang W, Jiang L, Song J. Clinical predictors of mortality due to COVID-19 based on an analysis of data of 150 patients from Wuhan,
China. Intensive Care Med. 2020 [cited 2020 May 5]; Available from: http:// link.springer.com/10.1007/s00134-020-05991-x.

41. Aziz M, Fatima R, Assaly R. Elevated interleukin-6 and severe COVID-19: A meta-analysis [published online ahead of print. J Med Virol. 2020;10.1002/ jmv.25948. https://doi.org/10.1002/jmv.25948.

42. Luo P, Liu Y, Qiu L, Liu X, Liu D, Li J. Tocilizumab treatment in COVID-19: A single center experience. J Med Virol. 2020;92(7):814-18. https://doi.org/10. 1002/jmv.25801.

43. Chen T, Wu D, Chen H, Yan W, Yang D, Chen G, et al. Clinical characteristics of 113 deceased patients with coronavirus disease 2019: retrospective study. BMJ. 2020;368:m1091. https://doi.org/10.1136/bmj.m1091.

44. Cai Q, Huang D, Ou P, Yu H, Zhu Z, Xia Z, et al. COVID-19 in a designated infectious diseases hospital outside Hubei Province, China [published online ahead of print, 2020 Apr 2]. Allergy. 2020;10.1111/all.14309. https://doi.org/ 10.1111/all.14309.

45. Mo P, Xing Y, Xiao Y, Deng $L$, Zhao Q, Wang H, et al. Clinical characteristics of refractory COVID-19 pneumonia in Wuhan, China [published online ahead of print, 2020 Mar 16]. Clin Infect Dis. 2020;ciaa270. https://doi.org/10. 1093/cid/ciaa270.

46. Wang D, Hu B, Hu C, Zhu F, Liu X, Zhang J, et al. Clinical characteristics of 138 hospitalized patients with 2019 novel coronavirus-infected pneumonia in Wuhan. China JAMA. 2020;323:1061.

47. Wang F, Hou H, Luo Y, Tang G, Wu S, Huang M, et al. The laboratory tests and host immunity of COVID-19 patients with different severity of illness. JCI Insight. 2020 [cited 2020 May 7]; Available from: http://insight.jci.org/ articles/view/137799.

48. Hou H, Zhang B, Huang H, Luo Y, Wu S, Tang G, et al. Using IL-2R/ lymphocytes for predicting the clinical progression of patients with COVID19 [published online ahead of print, 2020 May 4]. Clin Exp Immunol. 2020; 10.1111/cei.13450. https://doi.org/10.1111/cei.13450.

49. Mier JW, Gallo RC. Purification and some characteristics of human T-cell growth factor from phytohemagglutinin-stimulated lymphocyteconditioned media. Proc Natl Acad Sci. 1980;77:6134-8.

50. Smith K. Interleukin-2: inception, impact, and implications. Science. 1988;240: 1169-76.

51. Malek TR, Bayer AL. Tolerance, not immunity, crucially depends on IL-2. Nat Rev Immunol. 2004;4:665-74.

52. Nelson DL, Rubin LA, Kurman CC, Fritz ME, Boutin B. An analysis of the cellular requirements for the production of soluble interleukin-2 receptors in vitro. J Clin Immunol. 1986;6:114-20.

53. Minami $Y$, Kono T, Miyazaki T, Taniguchi $\mathrm{T}$. The $\mathrm{IL}-2$ receptor complex: its structure, function, and target genes. Annu Rev Immunol. 1993;11:245-68.

54. Rubin $\mathrm{L}$. The molecular basis for the generation of the human soluble interleukin 2 receptor. Cytokine. 1990;2:330-6.

55. Loughnan MS, Sanderson CJ, Nossal GJ. Soluble interleukin 2 receptors are released from the cell surface of normal murine B lymphocytes stimulated with interleukin 5. Proc Natl Acad Sci. 1988:85:3115-9.

56. Eurelings LEM, Miedema JR, Dalm VASH, van Daele PLA, van Hagen PM, van Laar JAM, et al. Sensitivity and specificity of serum soluble interleukin-2 receptor for diagnosing sarcoidosis in a population of patients suspected of sarcoidosis. Mogi M, editor. PLOS ONE. 2019;14:e0223897.

57. Maeda M, Tanabe-Shibuya J, Miyazato P, Masutani H, Yasunaga J-I, Usami K, et al. IL-2/IL-2 receptor pathway plays a crucial role in the growth and malignant transformation of HTLV-1-infected T cells to develop adult T-cell leukemia. Front Microbiol. 2020;11:356.

58. Krieg C, Letourneau S, Pantaleo G, Boyman O. Improved IL-2 immunotherapy by selective stimulation of IL-2 receptors on lymphocytes and endothelial cells. Proc Natl Acad Sci. 2010;107:11906-11.

59. Lodigiani C, lapichino G, Carenzo L, Cecconi M, Ferrazzi P, Sebastian T, et al. Venous and arterial thromboembolic complications in COVID-19 patients admitted to an academic hospital in Milan. Italy Thromb Res. 2020;191:9-14.

60. Klok FA, Kruip MJHA, van der Meer NJM, Arbous MS, Gommers DAMPJ, Kant $\mathrm{KM}$, et al. Incidence of thrombotic complications in critically ill ICU patients with COVID-19. Thromb Res. 2020;191:145-47. https://doi.org/10.1016/j. thromres.2020.04.013.

61. Dolhnikoff M, Duarte-Neto AN, de Almeida Monteiro RA, Ferraz da Silva LF, Pierre de Oliveira E, Nascimento Saldiva PH, et al. Pathological evidence of pulmonary thrombotic phenomena in severe COVID-19. J Thromb Haemost. 2020 [cited 2020 May 5]; Available from: http://doi.wiley.com/10.1111/jth.14844.

62. Pernazza A, Mancini M, Rullo E, Bassi M, De Giacomo T, Rocca CD, et al. Early histologic findings of pulmonary SARS-CoV-2 infection detected in a 
surgical specimen. Virchows Arch. 2020 [cited 2020 May 5]; Available from: http://link.springer.com/10.1007/s00428-020-02829-1.

63. Wichmann D, Sperhake J-P, Lütgehetmann M, Steurer S, Edler C, Heinemann A, et al. Autopsy findings and venous thromboembolism in patients with COVID19: a prospective cohort study. Ann Intern Med. 2020:M20-2003.

64. Tang N, Li D, Wang X, Sun Z. Abnormal coagulation parameters are associated with poor prognosis in patients with novel coronavirus pneumonia. J Thromb Haemost. 2020;18:844-7.

65. Gralinski LE, Bankhead A, Jeng S, Menachery VD, Proll S, Belisle SE, et al. Mechanisms of severe acute respiratory syndrome coronavirus-induced acute lung injury. Dermody TS, editor mBio. 2013;4:e00271-e00213.

66. Henry BM, Vikse J, Benoit S, Favaloro EJ, Lippi G. Hyperinflammation and derangement of renin-angiotensin-aldosterone system in COVID-19: a novel hypothesis for clinically suspected hypercoagulopathy and microvascular immunothrombosis. Clin Chim Acta. 2020;507:167-73.

67. Escher R, Breakey N, Lämmle B. Severe COVID-19 infection associated with endothelial activation. Thromb Res. 2020;190:62.

68. Magro C, Mulvey JJ, Berlin D, Nuovo G, Salvatore S, Harp J, et al. Complement associated microvascular injury and thrombosis in the pathogenesis of severe COVID-19 infection: a report of five cases [published online ahead of print, 2020 Apr 15]. Transl Res. 2020;220:1-13. https://doi. org/10.1016/j.trsl.2020.04.007.

69. Kuba K, Imai Y, Rao S, Gao H, Guo F, Guan B, et al. A crucial role of angiotensin converting enzyme 2 (ACE2) in SARS coronavirus-induced lung injury. Nat Med. 2005;11:875-9.

70. Lei C, Qian K, Li T, Zhang S, Fu W, Ding M, et al. Neutralization of SARS-CoV2 spike pseudotyped virus by recombinant ACE2-Ig. Nat Commun. 2020;11: 2070.

71. Vaduganathan M, Vardeny O, Michel T, McMurray JJV, Pfeffer MA, Solomon SD. Renin-angiotensin-aldosterone system inhibitors in patients with COVID-19. N Engl J Med. 2020;382:1653-9.

72. Zen M, Canova M, Campana C, Bettio S, Nalotto L, Rampudda M, et al. The kaleidoscope of glucorticoid effects on immune system. Autoimmun Rev. 2011:10:305-10.

73. Zielińska KA, Van Moortel L, Opdenakker G, De Bosscher K, Van den Steen PE. Endothelial response to glucocorticoids in inflammatory diseases. Front Immunol. 2016 [cited 2020 May 10];7. Available from: http://journal. frontiersin.org/article/10.3389/fimmu.2016.00592/full.

74. WHO WHO. Clinical management of severe acute respiratory infection when novel coronavirus (nCoV) infection is suspected. 13 March 2020. Available from: https://www.who.int/publications-detail/clinicalmanagement-of-severe-acute-respiratory-infection-when-novel-coronavirus(ncov)-infection-is-suspected.

75. Russell CD, Millar JE, Baillie JK. Clinical evidence does not support corticosteroid treatment for 2019-nCoV lung injury. Lancet. 2020;395:473-5.

76. Alhazzani W, Møller MH, Arabi YM, Loeb M, Gong MN, Fan E, et al. Surviving sepsis campaign: guidelines on the management of critically ill adults with coronavirus disease 2019 (COVID-19). Intensive Care Med. 2020;46:854-87.

77. Zha L, Li S, Pan L, Tefsen B, Li Y, French N, et al. Corticosteroid treatment of patients with coronavirus disease 2019 (COVID-19). Med J Aust. 2020 [cited 2020 May 10]; Available from: http://doi.wiley.com/10.5694/mja2.50577.

78. Wu C, Chen X, Cai Y, Xia J, Zhou X, Xu S, et al. Risk factors associated with acute respiratory distress syndrome and death in patients with coronavirus disease 2019 pneumonia in Wuhan, China. JAMA Intern Med. 2020 [cited 2020 May 10]; Available from: https://jamanetwork.com/journals/ jamainternalmedicine/fullarticle/2763184.

79. Mihara M, Kasutani K, Okazaki M, Nakamura A, Kawai S, Sugimoto M, et al. Tocilizumab inhibits signal transduction mediated by both $\mathrm{mLL}-6 \mathrm{R}$ and sIL$6 \mathrm{R}$, but not by the receptors of other members of IL- 6 cytokine family. Int Immunopharmacol. 2005;5:1731-40.

80. Xu X, Han M, Li T, Sun W, Wang D, Fu B, et al. Effective treatment of severe COVID-19 patients with tocilizumab. Proc Natl Acad Sci U S A. 2020;117(20): 10970-975. https://doi.org/10.1073/pnas.2005615117.

81. Sciascia S, Aprà F, Baffa A, et al. Pilot prospective open, single-arm multicentre study on off-label use of tocilizumab in patients with severe COVID-19. Clin Exp Rheumatol. 2020;38(3):529-32.

82. Kollias A, Kyriakoulis KG, Dimakakos E, Poulakou G, Stergiou GS, Syrigos K. Thromboembolic risk and anticoagulant therapy in COVID-19 patients: emerging evidence and call for action. Br J Haematol. 2020;189(5):846-47. https://doi.org/10.1111/bjh.16727.
83. Thachil J, Tang N, Gando S, Falanga A, Cattaneo M, Levi M, et al. ISTH interim guidance on recognition and management of coagulopathy in COVID-19. J Thromb Haemost. 2020;18:1023-6.

84. Tang N, Bai H, Chen X, Gong J, Li D, Sun Z. Anticoagulant treatment is associated with decreased mortality in severe coronavirus disease 2019 patients with coagulopathy. J Thromb Haemost. 2020;18:1094-9.

85. Susen S, Tacquard C-A, Godon A, Mansour A, Guarrigue D, Nguyen P, et al. Traitement anticoagulant pour la prévention du risque trombotique chez un patient hospitalisé avec Covid-19 et surveillance de l'hémostase propositions du GIHP et GFHT. 2020. Available from: https://www.portailvasculaire.fr/sites/ default/files/docs/covid-19_gihp-gfht-3_avril_final.pdf.

86. Bikdeli B, Madhavan MV, Jimenez D, Chuich T, Dreyfus I, Driggin E, et al. COVID-19 and Thrombotic or Thromboembolic Disease: Implications for Prevention, Antithrombotic Therapy, and Follow-up [published online ahead of print, 2020 Apr 15]. J Am Coll Cardiol. 2020;50735-1097(20)35008-7. https://doi.org/10.1016/j.jacc.2020.04.031.

87. Young E. The anti-inflammatory effects of heparin and related compounds. Thromb Res. 2008;122:743-52.

88. Li J, Vlodavsky I. Heparin, heparan sulfate and heparanase in inflammatory reactions. Thromb Haemost. 2009;102:823-8.

89. Wang J, Hajizadeh N, Moore EE, McIntyre RC, Moore PK, Veress LA, et al. Tissue plasminogen activator (tPA) treatment for COVID-19 associated acute respiratory distress syndrome (ARDS): a case series. J Thromb Haemost. 2020 [cited 2020 May 5]; Available from: http://doi.wiley.com/10.1111/jth.14828.

90. Jodele S, Medvedovic M, Luebbering N, Chen J, Dandoy CE, Laskin BL, et al. Interferon-complement loop in transplant-associated thrombotic microangiopathy. Blood Adv. 2020;4:1166-77.

91. Olson SR, Lu E, Sulpizio E, Shatzel JJ, Rueda JF, DeLoughery TG. When to stop eculizumab in complement-mediated thrombotic microangiopathies. Am J Nephrol. 2018:48:96-107.

92. Pittock SJ, Berthele A, Fujihara K, Kim HJ, Levy M, Palace J, et al. Eculizumab in aquaporin-4-positive neuromyelitis optica spectrum disorder. N Engl J Med. 2019:381:614-25.

93. Diurno F, Numis FG, Porta G, Cirillo F, Maddaluno S, Ragozzino A, et al. Eculizumab treatment in patients with COVID-19: preliminary results from real life ASL Napoli 2 Nord experience. Eur Rev Med Pharmacol Sci. 2020;24: 4040-7.

\section{Publisher's Note}

Springer Nature remains neutral with regard to jurisdictional claims in published maps and institutional affiliations. 